\title{
Website Features Influencing Online Shopping Mall Performance: Moderating Role of Product Involvement
}

\author{
Jungwon Lee \\ Korea University \\ d2liw510@naver.com
}

Okkyung Jung

Korea University

smallbaby21@hanmail.net

Yunhye Lee

Korea University

younhye@korea.ac.kr

Ohsung Kim

Korea University

osk800@naver.com

Cheol Park

Korea University

cpark@korea.ac.kr

\begin{abstract}
As the proportion of online shopping in the retail industry increases, studies on the effects of online shopping mall characteristics have been widely reported. However, limited research has been conducted on the effects of new website features in the Web2.0 environment and the factors that moderate these effects. This study analyzed these relationships through multilevel regression by measuring the features (e.g., decision aid, affiliate program, mobile app) of 390 online shopping malls and online shopping mall performance. The analysis showed that most website functions have a positive effect on online shopping malls, while the effect of product videos and affiliate programs differ by product involvement.
\end{abstract}

Keywords: e-Commerce, Website Feature, Product Involvement, Online Shopping Mall, Online Experience

\section{INTRODUCTION}

With the proliferation of mobile and internet technologies, the online retail industry has been growing. In particular, the growth of online shopping malls is accelerating due to the increase in demand for non-face-to-face consumption since Covid 19. According to eMarketer.com, a market research institute, global e-commerce sales are expected to 
increase from \$2.382 trillion in 2017 to $\$ 3.535$ trillion in 2019 and $\$ 4.26$ trillion in 2020, reaching $\$ 6.542$ trillion in $2023^{1}$. Overseas online shopping has also become more common, and the global online shopping market continues to grow. On the other side, offline distribution, known as "brick-and-mortar" is facing a crisis. For example, Macy's department stores in the United States have been struggling, experiencing a $5.2 \%$ decrease in peak season sales at the end of 2015, the closure of 40 offline stores in 2016, followed by the closure of another 66 offline stores in early 2017. As offline distribution continues to struggle, online retail is growing steadily every year. With the development of mobile and internet technologies, online shopping is expanding, and many offline stores are disappearing.

As the proportion of online shopping in the retail industry has increased, so have the studies on the characteristics of online shopping malls and customer reactions. One research strand relates to the quality of shopping malls [1]. According to a metaresearch by [2], the relevant literature has suggested information quality, interactivity, fulfillment, and ease of use as the criteria for evaluating websites, mainly through surveys and experimental research methods. Other research strand analyzed the impact of website design elements and features on consumer response [3]. For example, [4] analyzed the effect of product details, consumer word-of-mouth, and content filters on purchasing decisions. In addition, [5] analyzed the effect of a comparison matrix and recommendation agents on purchase intention. Thus, the functions and quality of online shopping malls are considered important factors influencing consumer behavior and online shopping mall performance [1].

However, most previous studies on the features of online shopping malls focused on individual-level performance, such as the attitudes of website users, as dependent variables [6]. Individual-level performance differs from corporate-level performance, and it is necessary to analyze the effect on corporate-level performance (e.g., sales) to provide realistic practical implications for website design. Another limitation of existing research is that as the era of Web 2.0, social media, and mobile ubiquity begins, it has become necessary to study the features of websites in new ways [7]. The features of Web 2.0 promote consumer participation in online shopping mall environments [8] and customer relationships [9]. Several researchers have conducted conceptual studies of new website features [10], but empirical studies are still limited. Futhermore, academic research typically focuses on a single design element or just a few across a limited number of products. It also often neglects the mechanisms through which design elements affect purchase or employs theoretical perspectives that conceptually limit their effects a priori to a single function [3].

It is also necessary to study the factors (i.e., involvement, [11]) that moderate the relationship between website features and performance [12-14]. According to a small number of prior studies, the effect of website features on online shopping mall performance may differ depending on the characteristics of products handled [3]. Therefore, the effect of online shopping mall features on performance is likely to vary depending on the level of consumer involvement, and exploring such moderating effects can provide considerable theoretical and practical implications.

Against this backdrop, this study analyzes the effect of website features on online shopping mall performance and the role of involvement in moderating these relationships by examining actual online shopping mall data. In addition, we intend to

\footnotetext{
1 See www.emarketer.com/content/global-ecommerce-2019
} 
expand the framework of the previous study and analyze the mechanism by which website features not covered in the previous study affect the performance of online shopping malls based on the affective, cognitive, and social dimensions.

For empirical analysis, 390 data were collected using the quota sampling method from the top 500 websites for 35 industry categories provided by Alexa. In addition, this study utilizes a multilevel analysis suitable for analyzing the multi-layered structure of industry and website factors that affect website performance. Through multilevel analysis, the explanatory power of industry and website factors affecting website performance can be estimated separately. As a result of the analysis, there was a difference in the moderating effect according to the level of involvement and functional characteristics that affect website performance.

We offer four main contributions to the literature. First, online customer experiences and identify three dimensions - namely, affactive, cognitive, and social - that act as the underlying mechanisms by which design elements influence purchase. Second, we found a positive effect on online shopping mall performance of Web 2.0 functions (e.g., affiliate program, decision aid, mobile app) that were not fully covered in previous studies. Third, we find that the effect of the website function on the online shopping mall performance is different according to the degree of involvement. Fourth, the results of this study provide actionable advice for marketers on how to strategically employ design features to form an effective online experience.

\section{THEORETICAL BACKGROUNDS}

\subsection{Website Design and Online Shopping Mall Performance}

The quality of online shopping malls is considered an important factor in attracting and retaining consumers [15-18]. Studies related to online shopping malls have explored effective criteria for evaluating website quality [2]. Prior studies focused predominantly on websites' design [19], content [20], quality [17,21], and user acceptance [16,22]. For example, [16] argued that the design of an online shopping mall's website has a strong impact on consumer behavior, as much as traditional retail services and low prices do. Moreover, consumers appear to visit and purchase from higher-quality websites $[17,18]$. According to prior literature, website design has a considerable effect on the immersion a consumer feels, and thus increases the likelihood that the user stays through conversion [3]. Most of previous studies on website design focused on visual design, navigation design, and information design [23]. Visual design refers to an external aspect that includes images, colors, fonts, shapes, animation, and layout of a website and has been reported to affect various consumer behaviors, such as ease of use, perceived usefulness, perceived enjoyment, and acceptance [24]. Navigation design is defined as the structure and organization of the content and pages of a website and is an important factor in determining how easily and quickly a user can get the desired information from a website with minimal effort. Information design indicates how well 
a website can deliver information that is appropriate for its users $[25,26]$ and has a positive effect on perceived ease of use and acceptance of online shopping [27].

In the context of design, research has also focused on the functional features of a website. Researchers have mainly analyzed the effect of website function on marketing performance [3]. For example, [28] reported that website information prosociality had a positive effect on website visibility. [4] analyzed the effects of consumer evaluation, detailed information, and content filters on purchase intention. However, research on the impact of Web 2.0 factors on online shopping mall performance is limited [10]. It also often neglects the mechanisms through which design elements affect purchase or employs theoretical perspectives that conceptually limit their effects a priori to a single function [3]. Exceptionally, [3] analyzed the effects of dimensions such as information, entertainment, social presence, and sensory appeal on product purchase. In this context, this study attempts to explore and empirically analyze the effects of various website features including Web 2.0 functions on online shopping mall performance through the consumer experience framework.

\subsection{Online Consumer Experience and Website Features}

We focus on the dimension of online consumer experience as a theoretical framework for integrating the relationship between these website features and online shopping mall performance into a single model. In sociology and psychology, cognition, affect, relation, and sensation are regarded as four basic dimensions. A broad stream of research conceptualizes offline experiences as consisting of multiple, separate, but related dimensions (e.g., cognitive, affective, sensory, social, physical) [29,30]. Compared to the focus on these dimensions, the online consumer experience dimension has been studied as a relatively simple dimension [31,32]. Yet research has treated online experiences far more simplistically [31,32], often a priori limited to their informativeness. We expect that this experience goes beyond cognitive (informativeness) and affective (entertainment) dimensions typically conceptualized in extant research [31] and also includes social (social presence; [33]).

In this study, we consider an affiliate program, product video, decision aid, and mobile app as Web 2.0 functions that are not fully covered in previous research. As the Web2.0, social media, and mobile ubiquity era began, functions that were previously impossible to implement have been realized [7]. Several researchers have conducted conceptual studies of new website features [10], but empirical studies are still scarce. Therefore, it is necessary to analyze the effect of website characteristics on the performance of online shopping malls through the online consumer experience framework. The main website features covered in this study are: 
- Video is a technical feature related to vividness, and practitioners and researchers are attempting to find a way to provide more sensory information [34,35]. Prior studies related to vividness focused mainly on the presence or absence of images and the characteristics of images [36], but research focusing on videos is limited.

- Affiliate programs provide incentives to encourage existing customers to recommend new customers [36-38]. Recently, studies have been reported on boundary conditions that moderate the effectiveness of affiliate programs [36]. However, research on the effectiveness of affiliate programs in the context of online shopping malls is limited.

- Decision aid provides decision support information on a website through interaction with consumers in making decisions in an online environment. There are different types, such as recommendation systems and a comparison matrix [5]. This study focused on the ability to provide price comparison information, one of the most important factors in an online shopping environment.

- Mobile app refers to a mobile application that enables mobile shopping [39]. The marketing literature analyzes the impact of mobile tools on consumer behavior [40].

- The volume of content is a quantitative variable regarding the information dimension of online shopping malls and is added as a website feature in this study because it has an important influence on consumer decision-making [20].

The classification of the characteristics of each factor into corresponding dimensions is shown in Figure 1. First, regardless of the ability to facilitate a particular shopping task, the immediate enjoyment that entertainment or experience provides is a key dimension of the online customer experience [41]. Images and videos are representative sensory appeal factors and classified into the affective dimension.

Second, informativeness, defined as "the extent to which a website provides consumers with resourceful and helpful information" [42], is the primary cognitive dimension of the online customer experience. Therefore, decision support and content volume are classified into the cognitive dimension as factors affecting the quality and quantity of information provided to consumers.

Finally, social presence refers to the warmth, sociability, and feeling of human contact that a web page confers [33]. Affiliate program and electronic word-of-mouth (eWOM) volume are classified into the social dimension as they affect the relationship between 
customers [9] as factors of Web2.0. Positive eWOM increase readers' intentions to buy a product [30]. In addition, the mobile app was added as a social dimension because it promotes instant exchange of information between shopping malls and users. This study measures the revenue of online shopping malls as a performance variable.

\subsection{Product Involvement}

The effect of website features on online shopping mall performance is likely to differ by the characteristics of the product being handled [3]. In purchasing decisions, involvement level is classified into high and low according to the degree of cognitive effort and time required to evaluate the product [31]. explained clarified the appropriate appeal methods according to involvement level through the elaboration likelihood model [43]. In the case of high-involvement, advertisements, and promotional messages aid the interpretation and processing of product information and form a central route of an active search. On the other hand, low-involvement involves a passive approach to searching for information and alternative evaluation with attitudes formed by peripheral routes, and thus require emotional appeal. This suggests that the method of appealing to customers through the message on the website should be changed according to the level of involvement. We focused on the role of involvement in moderating the impact of vividness (i.e., video) and affiliate program on online shopping mall performance.

First, in the case of low-involvement products, conveying simple, familiar, and interesting emotional properties (e.g., vividness) may be more effective. Therefore, the more the number of low-involvement products in a video, the higher the effect on online shopping mall performance.

Second, affiliate program involve recruiting new customers by encouraging existing customers to recommend the business to others [37,38]. It is an effective marketing strategy in that it not only helps recruit new customers, but also creates trust and ties with these customers who have been recommended the business by friends and acquaintances $[33,36]$. The core lever of this affiliate program is the reputation of the sender and the cost of action caused by the recipient participating in the services, such as purchasing an item or installing an app [44]. The higher the incentive, such as the sender's social reputation and reward, and the lower the recipient's cost of action, the more effective the affiliate program.

This may explain why a affiliate program may be more effective for a product that is of low involvement from the viewpoint of the product handled by the website. That is, in the case of low involvement, since the degree of interest and cognitive effort generated by the product are low, the action cost incurred when accepting the affiliate 
program is low, and thus, the effect of the program will be strengthened. Conversely, high-involvement products are likely to have a weakened effect because of the high perceived risk associated with action.

Summarizing the discussions so far, the research model is shown in Figure 1. Based on this model, this study answers the following questions.

- Research Question 1: How do website features affect online shopping mall performance?

- Research Question 2: Does product involvement moderate the effect of website features on online shopping mall performance?

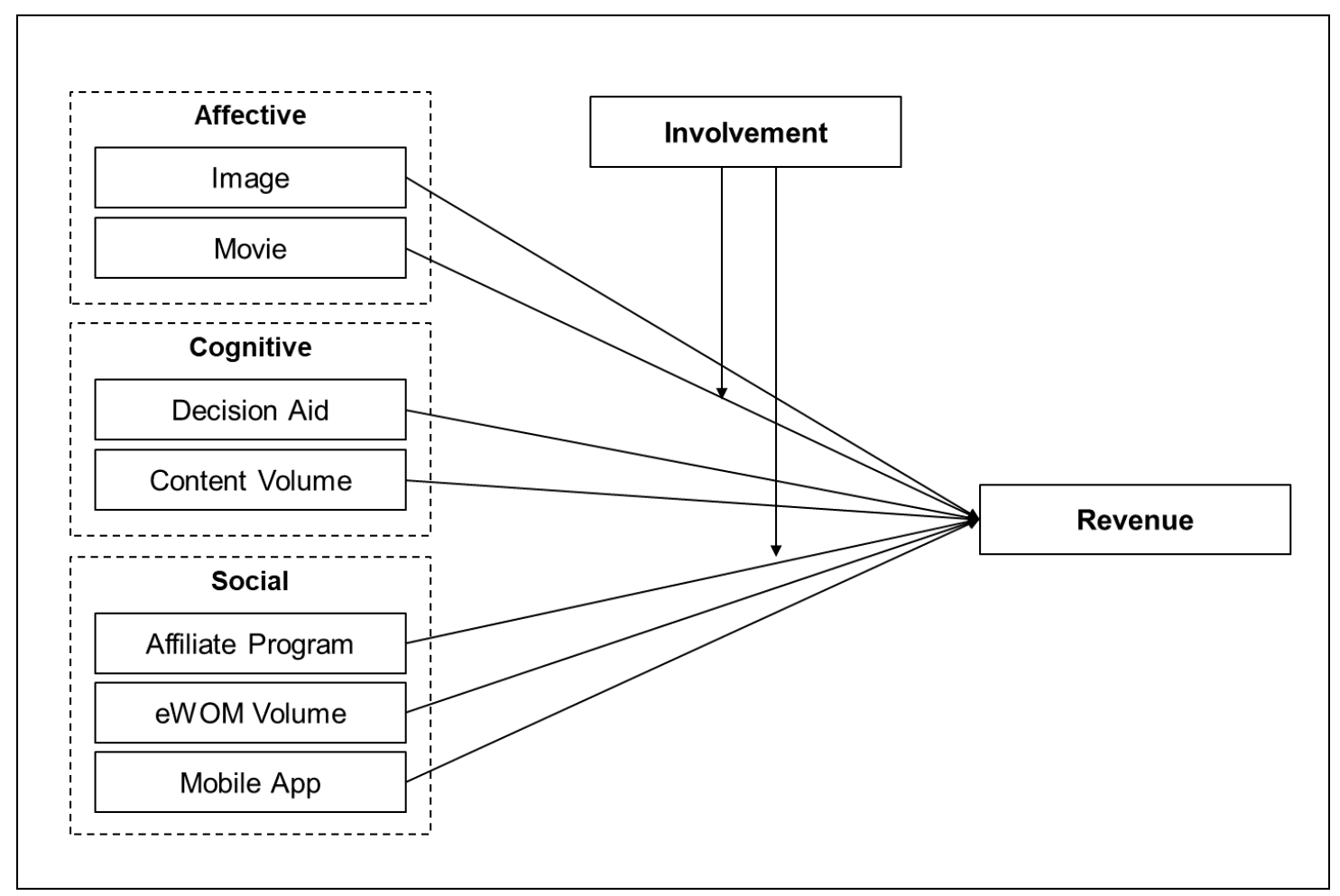

Figure 1. Research Model 


\section{METHODOLOGY}

\subsection{Sample and Variable Measurement}

In this study, data from 390 websites are collected from 35 industry categories provided by Alexa (www.alexa.com) to verify the effect of website features on online shopping mall performance. Alexa is a subsidiary of Amazon.com, which provides information on specific websites. It is a ranking site that provides website ranking, traffic volume, and keywords - information commonly available within the respective websites. Therefore, many studies have used Alexa for data collection and analysis. We select online shopping malls using the ranking list provided by Alexa. We used the quota sampling method to extract shopping mall sites from 35 industry categories classified by alexa. The total number of samples is 390 , and the sample distribution according to the category population is shown in Table 1 .

The measurement of the variable was carried out as follows. Site characteristics, an independent variable, were measured as dummy variables using the content analysis method [32]. First, website feature, an independent variable, is coded as 1 if a mobile app is operational, and 0 otherwise, and the number of images provided is measured. Decision support is coded as 1 when additional information is provided, such as price discount or comparison, and 0 otherwise, and the volume of eWOM is measured. The number of contents is measured by the number of contents registered on the website. Video is coded as 1 when video information about a shopping mall product is provided, and 0 otherwise. Affiliate program is coded as 1 when an affiliate program is operational, and 0 otherwise. An example of analysis of major variables is shown in the Figure 2 below. The characteristics provided by the actual website were checked and the variables were measured.

Coding was conducted in May 2019 by five researchers, and each variable was checked for the existence of a corresponding element. In order to increase the reliability of coding, the coding sheet for each factor is prepared before performing the coding. The reliability of the inter-coder analysis is calculated using Cohen's kappa, and the kappa value is .85 . 


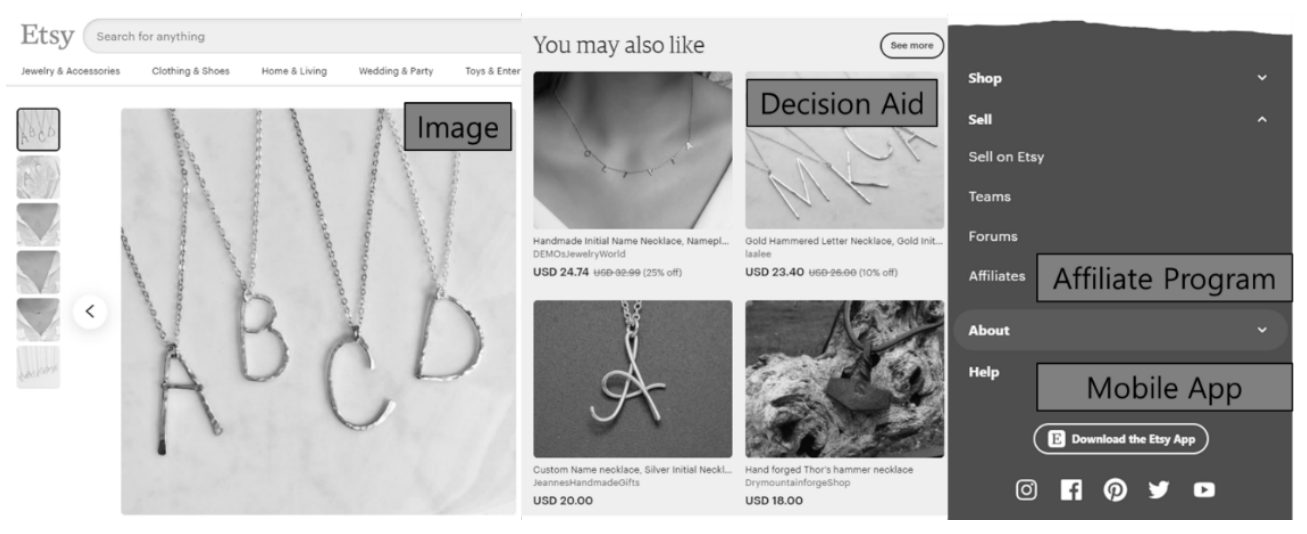

Figure 2. Content Analysis Example

Second, the website performance, the dependent variable, is calculated by summing the number of visitors to the website during July to September 2019; this number has been reported as the most important factor affecting company profitability. According to previous research [45], the number of visitors and time spent on a website is closely related to product purchase, and according to [28], the number of visitors to a website is directly related to sales. Thus, it can be regarded as a proxy variable for profit. The number of website visitors was measured using SimilarWeb (similarweb.com). SimilarWeb is a website that provides web analytics services for business. The backlinks (i.e., eWOM volume) of the websites are collected through neilpatel.com, and the total number of contents registered on the website is collected via Google (google.com) search.

Finally, the duration time and product type (hedonic vs. utilitarian) reported to have an effect on the online shopping mall performance were added as control variables. The duration time was measured in SimilarWeb in the same way as the number of visitors. The product type was classified by the content analysis method in the same way as the independent variable. In addition, normal distribution was verified by applying the natural logarithm where a positive skewness value was identified among independent variables.

\subsection{Data Analysis}

This study includes shopping mall-level variables and industry-level variables (product involvement). Ordinary least squares regression is not suitable for analyzing such multilevel data [46]; therefore, we apply multilevel regression. This method enables the calculation of the coefficients of the independent variables more accurately by simultaneously estimating the relationship between variables at the two levels through maximum likelihood estimation.

\subsection{Sample Characteristics}


This study selects 390 websites from 35 industry categories based on the shopping mall ranking list obtained by Alexa. Alexa calculates the rank based on a combination of daily visitors and page views for three months. To minimize the fluctuation of ranks, we visited the website (www.alexa.com) on September 30, 2019 and collected 390 website rankings, as shown in Table 1 below. Websites are collected by allocating the number of websites as a percentage of all websites according to sub-categories, and finally, a total of 390 websites are used for the analysis. The category with the largest number of websites is "Home and Garden," and 42 sites in this category are used for analysis. The categories with the least number of websites are "Weddings," "Death Care," and "Travel," and only one site in each category is used for analysis. The "Region" and "Directory" categories, which have the lowest ratio ( $0 \%$ on average) and are not generally applicable to online shopping malls, are excluded.

Table 1. Sample characteristics and proportions

\begin{tabular}{|c|c|c|c|c|c|c|c|c|c|}
\hline No & Category & Population & $\%$ & Sample & No & Category & Population & $\%$ & Sample \\
\hline 1 & $\begin{array}{c}\text { Home and } \\
\text { Garden }\end{array}$ & 6,259 & $10.82 \%$ & 42 & 18 & Gifts & 925 & $1.60 \%$ & 6 \\
\hline 2 & Food & 4,781 & $8.27 \%$ & 32 & 19 & Flowers & 732 & $1.27 \%$ & 5 \\
\hline 3 & Crafts & 4,711 & $8.15 \%$ & 32 & 20 & $\begin{array}{l}\text { Ethnic and } \\
\text { Regional }\end{array}$ & 717 & $1.24 \%$ & 5 \\
\hline 4 & Health & 3,946 & $6.82 \%$ & 27 & 21 & Children & 666 & $1.15 \%$ & 4 \\
\hline 5 & Sports & 3,922 & $6.78 \%$ & 26 & 22 & Tools & 587 & $1.02 \%$ & 4 \\
\hline 6 & Clothing & 3,668 & $6.34 \%$ & 25 & 23 & $\begin{array}{c}\text { General } \\
\text { Merchandise }\end{array}$ & 571 & $0.99 \%$ & 4 \\
\hline 7 & Recreation & 3,378 & $5.84 \%$ & 23 & 24 & $\begin{array}{c}\text { Office } \\
\text { Products }\end{array}$ & 518 & $0.90 \%$ & 3 \\
\hline 8 & Vehicles & 3,111 & $5.38 \%$ & 21 & 25 & Niche & 479 & $0.83 \%$ & 3 \\
\hline 9 & Visual Arts & 2,946 & $5.09 \%$ & 20 & 26 & Holidays & 443 & $0.77 \%$ & 3 \\
\hline 10 & $\begin{array}{l}\text { Antiques and } \\
\text { Collectibles }\end{array}$ & 2,498 & $4.32 \%$ & 17 & 27 & Photography & 415 & $0.72 \%$ & 3 \\
\hline 11 & Publications & 2,130 & $3.68 \%$ & 14 & 28 & Classifieds & 282 & $0.49 \%$ & 2 \\
\hline 12 & $\begin{array}{l}\text { Consumer } \\
\text { Electronics }\end{array}$ & 2,020 & $3.49 \%$ & 14 & 29 & Tobacco & 223 & $0.39 \%$ & 2 \\
\hline 13 & Entertainment & 1,684 & $2.91 \%$ & 11 & 30 & Auctions & 203 & $0.35 \%$ & 1 \\
\hline 14 & Jewelry & 1,629 & $2.82 \%$ & 11 & 31 & Weddings & 174 & $0.30 \%$ & 1 \\
\hline 15 & Pets & 1,438 & $2.49 \%$ & 10 & 32 & Death Care & 143 & $0.25 \%$ & 1 \\
\hline 16 & Music & 1,416 & $2.45 \%$ & 10 & 33 & Travel & 129 & $0.22 \%$ & 1 \\
\hline 17 & $\begin{array}{l}\text { Toys and } \\
\text { Games }\end{array}$ & 1,072 & $1.85 \%$ & 7 & Total & $6.82 \%$ & 57,816 & $100 \%$ & 390 \\
\hline
\end{tabular}




\section{Results}

First, basic statistics and correlation analysis of variables were conducted. Online shopping mall performance is positively correlated with content volume $(\rho=.196)$, eWOM volume $(\rho=.425)$, and mobile app $(\rho=.192)$ and negatively correlated with affiliate program $(\rho=-.140))$ and hedonic $(\rho=-.192)$.

Table 2. Results of correlation analysis of variables

\begin{tabular}{|c|c|c|c|c|c|c|c|c|c|c|c|}
\hline Variables & 1 & 2 & 3 & 4 & 5 & 6 & 7 & 8 & 9 & 10 & 11 \\
\hline 1. Image & 1 & & & & & & & & & & \\
\hline 2. Video & $.194^{* *}$ & 1 & & & & & & & & & \\
\hline 3. Decision Aid & -.029 & .067 & 1 & & & & & & & & \\
\hline 4. Content Volume & $-.084 *$ & .045 & $.128 * *$ & 1 & & & & & & & \\
\hline 5. eWOM Volume & -.047 & -.047 & -.026 & $.198 * *$ & 1 & & & & & & \\
\hline 6. Affiliate Program & -.026 & .087 & $.296 * *$ & $.160 * *$ & -.012 & 1 & & & & & \\
\hline 7. Mobile App & -.016 & -.059 & -.002 & .040 & $.232 * *$ & $-.139 * *$ & 1 & & & & \\
\hline 8. Duration Time & -.042 & .031 & $.089 *$ & .017 & $.070 *$ & .007 & .016 & 1 & & & \\
\hline 9. Low Involvement & .009 & -.068 & $-.293 * *$ & $-.163 * *$ & $.157 * *$ & $-.249 * *$ & .003 & -.060 & 1 & & \\
\hline 10. Hedonic & .071 & .038 & $.191 * *$ & $.132 * *$ & $-.143 * *$ & $.100 *$ & -.032 & $.096^{*}$ & $-.140 * *$ & 1 & \\
\hline 11. Revenue & -.004 & .025 & -.007 & $.196 * *$ & $.425^{* *}$ & $-.140 * *$ & $.291 * *$ & .048 & .067 & $-.192 * *$ & 1 \\
\hline Mean & 4.59 & 0.32 & 0.50 & 13.42 & 12.82 & 0.39 & 0.51 & 5.45 & 0.56 & 0.67 & 14.9 \\
\hline $\mathrm{SD}$ & 3.31 & 0.47 & 0.50 & 3.00 & 2.41 & 0.49 & 0.50 & 0.42 & 0.50 & 0.47 & 3.2 \\
\hline Min & 0.00 & 0.00 & 0.00 & 3.43 & 3.51 & 0.00 & 0.00 & 3.40 & 0.00 & 0.00 & 6.7 \\
\hline $\operatorname{Max}$ & 10.00 & 1.00 & 1.00 & 21.93 & 21.30 & 1.00 & 1.00 & 6.53 & 1.00 & 1.00 & 22.9 \\
\hline
\end{tabular}

Second, the results of analyzing the research problem are as follows. Model 1 presents the analysis results for the effect of website-level features on the performance of online shopping malls. Specifically, image $(\beta=.005 ; p<.01)$, decision aid $(\beta=.049 ; p<.01)$, content volume $(\beta=.019 ; p<.01)$, eWOM volume $(\beta=.027 ; p<.01)$, and mobile app $(\beta=.039 ; p<.01)$ have a positive effect on online shopping mall performance. Meanwhile, affiliate program $(\beta=-.076 ; p<.01)$ has a negative effect on online shopping mall performance, and video $(\beta=.015 ; p>.05)$ has no statistically significant effect. The analysis results of the moderating role of involvement in the relationship between website features and online shopping mall performance are presented in Model 3. In industries with low involvement, the positive effect of video is strengthened compared to industries with high involvement $(\beta=.068 ; p<.01)$, and the negative effect of affiliate program is weakened $(\beta=.119 ; p<.01)$.

In addition, it was found that the model (3), which analyzed the interaction effect of the degree of involvement, had better fit of the model than the model (1) and the model (2). 
In addition, it was found that both website level variance and industry level variance decreased in model (3). Therefore, the multilevel analysis of this study is judged to be appropriate, and it can be confirmed that the effect of involvement is also an important factor in online shopping mall performance.

Table 3. Hypothesis Test Results

\begin{tabular}{|c|c|c|c|}
\hline Variables & (1) & (2) & (3) \\
\hline Intercept & $\begin{array}{c}2.015^{* * *} \\
(0.111)\end{array}$ & $\begin{array}{c}2.048 * * * \\
(0.113)\end{array}$ & $\begin{array}{c}2.132 * * * \\
(0.112)\end{array}$ \\
\hline \multicolumn{4}{|l|}{ Website Level } \\
\hline Image & $\begin{array}{l}0.005^{* *} \\
(0.002)\end{array}$ & $\begin{array}{l}0.005^{* *} \\
(0.002)\end{array}$ & $\begin{array}{l}0.004 * \\
(0.002)\end{array}$ \\
\hline Video & $\begin{array}{c}0.015 \\
(0.016)\end{array}$ & $\begin{array}{c}0.015 \\
(0.016)\end{array}$ & $\begin{array}{l}-0.027 \\
(0.023)\end{array}$ \\
\hline Decision Aid & $\begin{array}{l}0.049^{* *} \\
(0.015)\end{array}$ & $\begin{array}{l}0.042 * * \\
(0.016)\end{array}$ & $\begin{array}{l}0.039^{* *} \\
(0.015)\end{array}$ \\
\hline Content Volume & $\begin{array}{c}0.019^{* * *} \\
(0.003)\end{array}$ & $\begin{array}{c}0.018^{* * *} \\
(0.004)\end{array}$ & $\begin{array}{r}0.016^{* * *} \\
(0.003)\end{array}$ \\
\hline eWOM Volume & $\begin{array}{c}0.027 * * * \\
(0.003)\end{array}$ & $\begin{array}{c}0.029 * * * \\
(0.004)\end{array}$ & $\begin{array}{c}0.028 * * * \\
(0.003)\end{array}$ \\
\hline Affiliate Program & $\begin{array}{c}-0.076^{* * *} \\
(0.016)\end{array}$ & $\begin{array}{c}-0.080^{* * *} \\
(0.016)\end{array}$ & $\begin{array}{r}-0.143 * * * \\
(0.023)\end{array}$ \\
\hline Mobile App & $\begin{array}{l}0.039 * * \\
(0.015)\end{array}$ & $\begin{array}{r}0.035^{* *} \\
(0.015)\end{array}$ & $\begin{array}{l}0.037^{* *} \\
(0.015)\end{array}$ \\
\hline Average Duration Time & $\begin{array}{l}0.027 \\
(0.017)\end{array}$ & $\begin{array}{c}0.024 \\
(0.017)\end{array}$ & $\begin{array}{c}0.022 \\
(0.017)\end{array}$ \\
\hline \multicolumn{4}{|l|}{ Industry Level } \\
\hline Low Involvement & & $\begin{array}{c}-0.033^{* *} \\
(0.016)\end{array}$ & $\begin{array}{c}-0.103^{* * *} \\
(0.022)\end{array}$ \\
\hline Hedonic (vs. Utilitarian) & $\begin{array}{c}-0.075^{* * *} \\
(0.018)\end{array}$ & $\begin{array}{c}-0.077^{* * *} \\
(0.018)\end{array}$ & $\begin{array}{c}-0.056^{* *} \\
(0.019)\end{array}$ \\
\hline \multicolumn{4}{|l|}{ Interaction Terms } \\
\hline Video $\times$ Low Involvement & & & $\begin{array}{l}0.068^{* *} \\
(0.031)\end{array}$ \\
\hline $\begin{array}{l}\text { Affiliate Program } \times \text { Low } \\
\text { Involvement }\end{array}$ & & & $\begin{array}{c}0.119^{* * *} \\
(0.032)\end{array}$ \\
\hline \multicolumn{4}{|l|}{ Model Fit } \\
\hline Observations & 390 & 390 & 390 \\
\hline
\end{tabular}


Table 3. Hypothesis Test Results

\begin{tabular}{|l|c|c|c|}
\hline Model Fit & (1) & (2) & (3) \\
\hline Website Level Variance & 0.019775 & 0.019612 & 0.01872 \\
\hline Industry Level Variance & 0.004152 & 0.004557 & 0.00426 \\
\hline AIC & -402.41 & -404.48 & -420.81 \\
\hline BIC & -354.82 & -352.92 & -361.32 \\
\hline $\operatorname{logLik}$ & 213.21 & 215.24 & 225.41 \\
\hline Chi-squared Test & & $\Delta 4.065(\mathrm{df}=1)^{*}$ & $\begin{array}{c}\Delta 20.332 \\
(\mathrm{df}=2)^{* * *}\end{array}$ \\
\hline
\end{tabular}

$* \mathrm{p}<0.05 ; * * \mathrm{p}<0.01 ; * * * \mathrm{p}<0.001$

Finally, the results of analyzing marginal effects are summarized in Figure 3. The Y axis represents performance of online shopping malls, and the $\mathrm{X}$ axis represents each shopping mall features. We analyzed the variation of the marginal effects according to product involvement.

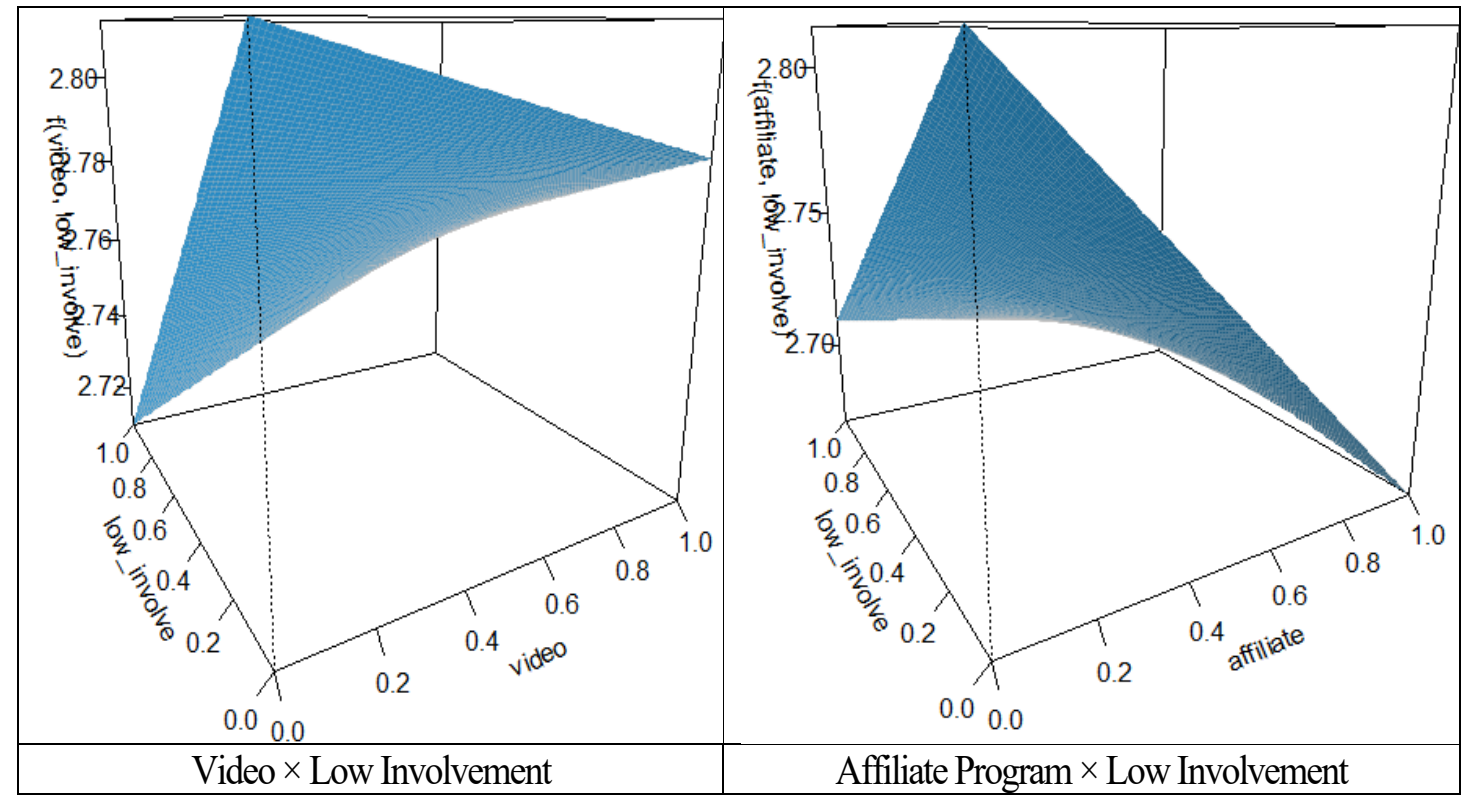

Figure 3. Marginal effects analysis

\section{Conclusion}

\subsection{Theoretical Contribution}

This study has several theoretical contributions. First, online customer experiences and identify three dimensions - namely, emotional, cognitive, and social — that act as the underlying mechanisms by which design elements influence purchase. Prior research typically focuses on a single design element or just a few across a limited number of products. It also often neglects the mechanisms through which design elements affect purchase or employs theoretical perspectives that conceptually limit their effects a 
priori to a single function [3]. In this context, this study has a theoretical contribution to the synthesis of mechanisms in which various website features affect online shopping mall performance through a consumer experience framework into one model.

Second, we found a positive effect on online shopping mall performance of Web 2.0 functions (e.g., affiliate program, decision aid, mobile app) that were not fully covered in previous studies. The features of Web 2.0 promote consumer participation in online shopping mall environments [8] and customer relationships [9]. Several researchers have conducted conceptual studies of new website features [10], but empirical studies are still limited. The results of this study contributed to the literature by presenting the effect of web 2.0 function on online shopping mall performance.

Third, we find that involvement about the product influences the effects of the website features on online shopping mall performance. The effect of website features on online shopping mall performance is likely to differ by the characteristics of the product being handled [3]. However, previous studies analyzing boundary conditions for the effectiveness of website features are limited. This study expanded the online shopping mall literature by suggesting that there is a difference in the influence of video and affiliate programs on website performance according to consumer involvement.

Fourth, since most of the online shopping mall design studies were conducted in a survey or experiment, there is a limit to verifying the external validity of the effect of the website feature. This study can complement the results of previous studies by analyzing actual online shopping mall data of various industries through quata sampling method.

\subsection{Practical Implications}

The results of this study provide some actionable advice to marketers on how to strategically use design elements to increase online shopping mall performance.

First, an increase in the number of images and content for products sold on a website have a positive effect on website performance. Providing sufficient content and images of products helps users obtain rich information and thus make more informed decisions, which will increase the reliability and satisfaction of the website. Therefore, it is necessary to provide adequate images and content on websites.

Second, the decision support function has a positive effect on online shopping mall performance. This enhances convenience for uses through supporting information on the website in making decisions. Therefore, companies should install a service function on the website to enable the comparison of product prices.

Third, the presence or absence of video on the website has a positive effect on online shopping mall performance as it is a low-involvement product. Due to the nature of 
high-involvement products, specific and practical messages about the functional and physical characteristics of the products are needed. However, in the case of lowinvolvement products, user interest can be increased through videos with emotional appeal.

Fourth, the amount of eWOM has a positive effect on various related outcomes of online shopping mall performance, such as sales and consumer awareness. In particular, consumer reviews can increase the reliability of shopping malls by providing a variety of information to new users. Therefore, practitioners should operate their own social media platform and manage consumer reviews to enhance online shopping mall performance.

Fifth, in previous studies, economic incentives through affiliate programs were found to increase the eWOM and performance. However, in this study, the affiliate program has a negative effect on online shopping mall performance. In addition, this negative effect is weaker for low-involvement products. Therefore, it is necessary to emphasize the implementation of affiliate programs. To increase the effectiveness of affiliate programs, practitioners need to develop a device that can lower the cost of action through free trial services and promotions that users can easily participate in, rather than simply encouraging purchases.

Sixth, mobile apps have a positive effect on online shopping mall performance. Consumers can easily access websites through mobile apps. Website practitioners can tap into new sales opportunities by developing and operating mobile apps for the convenience of mobile users.

\subsection{Limitations and Further Research}

The limitations of this study are as follows. First, this study analyzed the characteristics of various online shopping malls by dividing them into affective, cognitive, and social dimensions of consumer experience. Since this framework is a dimension of consumer experience, it is difficult to verify the reliability and validity of the dimension with data measured with dummy variables of the characteristics of individual websites. Therefore, in future research, it is necessary to verify the reliability and validity of the experience dimension of the characteristics of various online shopping malls in the dimensions of affective, cognitive, and social through a survey of consumers.

Second, it is necessary to consider various variable types of shopping malls or cultural variables as adjustment variables. For example, the degree to which website features affect online shopping mall performance may vary depending on the culture.

Third, it is necessary to study the factors that affect not only online purchases but also mobile purchases discussed in this study. In particular, in this study, the presence or absence of a mobile app was measured, but future research should study the effect of various characteristics of mobile apps on mobile purchases. 


\section{CITATIONS}

[1] M. Wolfinbarger and M. C. Gilly, "eTailQ: Dimensionalizing, measuring and predicting etail quality," Journal of Retailing, vol. 79, no. 3, pp. 183-198, 2003.

[2] W.-C. Chiou, C.-C. Lin, and C. Perng, "A strategic framework for website evaluation based on a review of the literature from 1995-2006," Information \& Management, vol. 47, no. 5-6, pp. 282-290, 2010.

[3] A. Bleier, C. M. Harmeling, and R. W. Palmatier, "Creating effective online customer experiences," Journal of Marketing, vol. 83, no. 2, pp. 98-119, 2018.

[4] J. R. Hauser, G. L. Urban, G. Liberali, and M. Braun, "Website morphing," Marketing Science, vol. 28, no. 2, pp. 202-223, 2009.

[5] G. Häubl and V. Trifts, "Consumer decision making in online shopping environments: The effects of interactive decision aids," Marketing Science, vol. 19, no. 1, pp. 4-21, 2000.

[6] D.-M. Koo and S.-H. Ju, "The interactional effects of atmospherics and perceptual curiosity on emotions and online shopping intention," Computers in Human Behavior, vol. 26, no. 3, pp. 377-388, 2010.

[7] A. M. Kaplan and M. Haenlein, "Users of the world, unite! The challenges and opportunities of social media,” Business Horizons, vol. 53, no. 1, pp. 59-68, 2010.

[8] Y. A. Kim and J. Srivastava, "Impact of social influence in e-commerce decision making," Proceedings of the ninth international conference on Electronic commerce - ICEC '07, MN, USA, 2007, pp.293-302.

[9] T.-P. Liang, Y.-T. Ho, Y.-W. Li, and E. Turban, "What drives social commerce: the role of social support and relationship quality," International Journal of Electronic Commerce, vol. 16, no. 2, pp. 69-90, 2011.

[10] Z. Huang and M. Benyoucef, "From e-commerce to social commerce: A close look at design features," Electronic Commerce Research and Applications, vol. 12, no. 4, pp. 246-259, 2013.

[11] E. P. Krugman, Consumer Behavior and Advertising Involvement, Routledge, 2013.

[12] H. Barki and J. Hartwick, "Measuring user participation, user involvement, and user attitude," MIS Quarterly, vol. 18, no. 1, p. 59, 1994.

[13] J. L. Zaichkowsky, "Conceptualizing Involvement," Journal of Advertising, vol. 15, no. 2, pp. 4-34, 1986.

[14] G. Laurent and J.-N. Kapferer, "Measuring consumer involvement profiles," Journal of Marketing Research, vol. 22, no. 1, p. 41, 1985.

[15] S. A. Eroglu, K. A. Machleit, and L. M. Davis, "Atmospheric qualities of online retailing," Journal of Business Research, vol. 54, no. 2, pp. 177-184, 2001. 
[16] M. Koufaris, "Applying the technology acceptance model and flow theory to online consumer behavior," Information Systems Research, vol. 13, no. 2, pp. 205-223, 2002.

[17] V. Patel, K. Das, R. Chatterjee, and Y. Shukla, "Does the interface quality of mobile shopping apps affect purchase intention? An empirical study," Australasian Marketing Journal, 2020.

[18] S. Mithas, N. Ramasubbu, M. S. Krishnan, and C. Fornell, "Designing web sites for customer loyalty across business domains: a multilevel analysis," Journal of Management Information Systems, vol. 23, no. 3, pp. 97-127, 2006.

[19] R. Agarwal and V. Venkatesh, “Assessing a firm's web presence: A heuristic evaluation procedure for the measurement of usability," Information Systems Research, vol. 13, no. 2, pp. 168-186, 2002.

[20] S. Baloglu and Y. A. Pekcan, "The website design and Internet site marketing practices of upscale and luxury hotels in Turkey," Tourism Management, vol. 27, no. 1, pp. 171-176, 2006.

[21] S. J. Barnes and R. Vidgen, "An evaluation of cyber-bookshops: The webqual method," International Journal of Electronic Commerce, vol. 6, no. 1, pp. 11-30, 2001.

[22] P. Virdi, A. D. Kalro, and D. Sharma, "Online decision aids: the role of decisionmaking styles and decision-making stages," International Journal of Retail \& Distribution Management, vol. 48, no. 6, pp. 555-574, 2020.

[23] Y. Gao and M. Koufaris, "Perceptual antecedents of user attitude in electronic commerce," ACM SIGMIS Database, vol. 37, no. 2-3, p. 42, 2006.

[24] S. Kim and L. Stoel, "Dimensional hierarchy of retail website quality," Information \& Management, vol. 41, no. 5, pp. 619-633, 2004.

[25] J.-R. Fu, I.-W. Lu, J. H. Chen, and C.-K. Farn, "Investigating consumers' online social shopping intention: An information processing perspective," International Journal of Information Management, vol. 54, p. 102189, 2020.

[26] Y. Lee and K. A. Kozar, "Investigating the effect of website quality on e-business success: An analytic hierarchy process (AHP) approach," Decision Support Systems, vol. 42, no. 3, pp. 1383-1401, 2006.

[27] H.-P. Shih, "An empirical study on predicting user acceptance of e-shopping on the Web," Information \& Management, vol. 41, no. 3, pp. 351-368, 2004.

[28] G. Pant and S. Pant, "Visibility of corporate websites: The role of information prosociality," Decision Support Systems, vol. 106, pp. 119-129, 2018.

[29] J. J. Brakus, B. H. Schmitt, and L. Zarantonello, "Brand experience: what is it? how is it measured? does it affect loyalty?," Journal of Marketing, vol. 73, no. 3, pp. 52-68, 2009. 
[30] K. N. Lemon and P. C. Verhoef, "Understanding customer experience throughout the customer journey," Journal of Marketing, vol. 80, no. 6, pp. 69-96, 2016.

[31] T. P. Novak, D. L. Hoffman, and Y. F. Yung, "Measuring the customer experience in online environments: A structural modeling approach," Marketing Science, vol. 19, no. 1, pp. 22-42, 2000.

[32] J.-B. E. Steenkamp and I. Geyskens, "How country characteristics affect the perceived value of web sites," Journal of Marketing, vol. 70, no. 3, pp. 136-150, 2006.

[33] S. A. Andel, G. J. De Vreede, and P. E. Spector, "Do social features help in videocentric online learning platforms? A social presence perspective," Computers in Human Behavior, vol. 113, 106505, 2020.

[34] J. R. Coyle and E. Thorson, "The effects of progressive levels of interactivity and vividness in web marketing sites," Journal of Advertising, vol. 30, no. 3, pp. 6577, 2001.

[35] R. Gershon and C. Cryder, "Goods donations increase charitable credit for lowwarmth donors," Journal of Consumer Research, vol. 45, no. 2, pp. 451-469, 2017.

[36] X. Y. Leung, B. Bai, and M. Erdem, "Hotel social media marketing: a study on message strategy and its effectiveness," Journal of Hospitality and Tourism Technology, vol. 8, no. 2, pp. 239-255, 2017.

[37] P. Schmitt, B. Skiera, and C. V. D. Bulte, "Referral programs and customer value," Journal of Marketing, vol. 75, no. 1, pp. 46-59, 2011.

[38] B. Edelman, and W. Brandi, "Risk, information, and incentives in online affiliate marketing," Journal of Marketing Research, vol. 52 no. 1, pp. 1-12, 2015.

[39] R. Gershon, C. Cryder, and L. K. John, "Why prosocial referral incentives work: the interplay of reputational benefits and action costs," Journal of Marketing Research, vol. 57, no. 1, pp. 156-172, 2019.

[40] L. Grewal and A. T. Stephen, "In mobile we trust: the effects of mobile versus nonmobile reviews on consumer purchase intentions," Journal of Marketing Research, vol. 56, no. 5, pp. 791-808, 2019.

[41] B. J. Babin, W. R. Darden, and M. Griffin, "Work and/or fun: measuring hedonic and utilitarian shopping value," Journal of Consumer Research, vol. 20, no. 4, pp. 644-656, 1994.

[42] W. M. Lim and D. H. Ting, "E-shopping: An analysis of the uses and gratifications theory," Modern Applied Science, vol. 6, no. 5, pp. 48-63, 2012.

[43] R. E. Petty and J. T. Cacioppo, "The elaboration likelihood model of persuasion," Communication and Persuasion, pp. 1-24, 1986.

[44] G. Ryu and L. Feick, "A penny for your thoughts: referral reward programs and 
referral likelihood," Journal of Marketing, vol. 71, no. 1, pp. 84-94, 2007.

[45] W. W. Moe and P. S. Fader, "Capturing evolving visit behavior in clickstream data," Journal of Interactive Marketing, vol. 18, no. 1, pp. 5-19, 2004.

[46] S. W. Raudenbush, "Educational applications of hierarchical linear models: a review," Journal of Educational Statistics, vol. 13, no. 2, p. 85, 1988. 
